\title{
约 \\ NEM LOCALISTAS NEM SETORIALISTAS, AS ASSEMBLEIAS ESTADUAIS SÃO "CLASSE-MÉDISTAS": GANHOS E PERDAS DAS LEIS ESTADUAIS DURANTE A CRISE DA COVID-19
}

\author{
NEITHER LOCALISTS NOR SECTORIALISTS, STATE ASSEMBLIES ARE \\ "MIDDLE CLASS": BENEFITS AND LOSSES OF STATE LAWS DURING \\ THE COVID-19 CRISIS
}

\author{
NI LOCALISTAS NI SECTORIALISTAS, LAS ASAMBLEAS ESTATALES \\ SON “CLASE MEDISTAS”: GANANCIAS Y PÉRDIDAS DE LAS LEYES \\ ESTATALES DURANTE LA CRISIS DEL COVID-19
}

\author{
Murilo de Oliveira Junqueira ${ }^{1}$
}

\begin{abstract}
Resumo O presente artigo visa analisar o conteúdo das leis aprovadas pelas Assembleias estaduais no combate à crise econômica e social gerada pela Covid-19. Foram analisadas 309 leis de dezesseis estados brasileiros. A metodologia utilizada foi a análise de conteúdo e a análise exploratória de dados. Observouse que o padrão de relações entre Assembleia Legislativa e governos de Estado variou enormemente, sendo que alguns parlamentos aprovaram muitas leis e outros pouquíssimas. Principalmente nos parlamentos que aprovaram muitas leis, houve um notável aumento do intervencionismo econômico, principalmente em medidas que beneficiavam, de forma difusa, a classe média. Esse achado contraria o esperado pela literatura, que preconiza que o maior interesse dos parlamentares são medidas de interesse local ou setorial.
\end{abstract}

Palavras-chave: Federalismo; Covid-19; Políticas Públicas; Estudos Legislativos; Política Estadual

\begin{abstract}
This aim of this paper is to analyze the content of the state's laws in the fight against the economic and social crisis generated by Covid-19. Sixteen Brazilian states were analyzed, including 309 laws. The methodology used was content analysis and exploratory data analysis. It was observed that the pattern of relations between the Legislative Assembly and State governments varied enormously, with some parliaments passing many laws and others very few. Especially in the parliaments that passed many laws, there was a notable increase in economic interventionism, mainly in policies that benefited, in a diffuse way, the middle class. This finding is contrary to what is expected by the literature, which advocates that the greatest interest of parliamentarians are measures of local or sectorial interest.
\end{abstract}

Keyword: Federalism; Covid-19; Public Policy; Legislative Studies; State Policy

Resumen Este artículo tiene como objetivo analizar el contenido de las leyes aprobadas por las Asambleas del Estado en la lucha contra la crisis económica y social generada por Covid-19. Se analizaron 309 leyes de dieciséis estados brasileños. La metodología utilizada fue el análisis de contenido y el análisis exploratorio de datos. Se observó que el patrón de relaciones entre la Asamblea Legislativa y los gobiernos de los estados varió enormemente, con algunos parlamentos aprobando muchas leyes y otros muy pocas. Especialmente en los parlamentos que aprobaron muchas leyes, hubo un aumento notable del intervencionismo económico, principalmente en medidas que beneficiaron, de manera difusa, a la clase media. Este hallazgo es contrario a lo esperado por la literatura, que defiende que el mayor interés de los parlamentarios son las medidas de interés local o sectorial.

Palabra clave: Federalismo; Covid-19; Política Pública; Estudios Legislativos; Política Estatal

\footnotetext{
${ }^{1}$ Universidade Federal do Pará.
} 


\section{Introdução}

O ano de 2020 foi marcado pela pandemia da Covid-19, causada por um tipo até então desconhecido de Coronavírus. A pandemia se alastrou fortemente pelo globo e atingiu duramente o Brasil. Nas terras tupiniquins, o governo federal teve uma postura relativamente ausente da crise, se abstendo criar uma estratégia nacional unificada de enfrentamento ao vírus e à crise econômica provocada por ele. Assim, os Estados foram, em grande medida, entregues à própria sorte e tiveram que combater, cada um ao seu modo, os problemas sanitários, econômicos e sociais causados pela doença.

Essa situação, apesar de trágica do ponto de vista humano, fornece uma excelente oportunidade de analisar como poderia ter sido o enfrentamento da crise se houvesse outro governo no comando do país. Cada Estado é um pequeno governo, com certo grau de autonomia, segundo o princípio federativo. A autonomia estadual, em um contexto em que o governo federal se absteve de agir, torna a federação brasileira um "laboratório de políticas públicas", pois um mesmo desafio foi enfrentado de várias maneiras diferentes. Evidentemente, o alcance das políticas sob competência estadual é bem menor que o alcance das políticas federais (ARRETCHE, 2005; GUICHENEY; JUNQUEIRA; ARAÚJO, 2018; TOMIO; ORTOLAN; CAMARGO, 2010). No entanto, é possível inferir das medidas estaduais um "estilo" de enfrentamento da crise, o que nos permite especular sobre o que teria acontecido se houvesse outro governante em Brasília. Esse artigo pretende, então, explorar o que cada unidade federativa fez do ponto de vista legislativo, principalmente com relação a propostas que geram ganhadores e perdedores ${ }^{2}$. Apesar de o governo estadual poder implementar de facto muitas políticas contando exclusivamente com medidas administrativas, dado o princípio da legalidade, certas medidas somente são legítimas se forem amparadas por lei, logo, pela colaboração com as Assembleias Legislativas estaduais. Podemos citar, como exemplo, medidas tributárias, criação de novos benefícios sociais, alteração na remuneração de servidores ou novos direitos do consumidor.

Como a análise abaixo demonstra, a diversidade de estratégias do "laboratório federativo" brasileiro foi enorme. Houve desde casos em que as Assembleias Legislativas pouco fizeram, aprovando um número reduzidíssimo de leis, até casos em que foram aprovadas dezenas de leis, sendo a grande maioria de autoria dos próprios parlamentares. Essas leis estão longe de serem leis simbólicas ou "de baixo impacto". Pelo contrário, os parlamentos estaduais promoveram um notável aumento do intervencionismo econômico. Vários estados aprovaram leis que propunham congelamento de preços, cotas de compras por consumidor ou redução forçada dos preços de

\footnotetext{
${ }^{2}$ A versão inicial desse artigo continha uma sessão inteira sobre analisando as políticas de saúde, onde muitas propostas não possuem perdedores e ganhadores claros (pense em uma política de prevenção, por exemplo). Contudo, dada a complexidade do tema e as limitações desse espaço, iremos nos analisar apenas as medidas das demais áreas, reservando para um artigo em separado as políticas de saúde.
} 
certos produtos. Assim, podemos perceber que, em alguns Estados, o contexto da pandemia mudou os incentivos dos legisladores em direção ao ativismo legal, tal como ocorre no contexto de grandes crises econômicas ou guerras (ARNOLD, 1992; LEVI, 1989).

Além de analisar a diversidade de políticas dos Estados, o presente artigo visa também elucidar o comportamento dos parlamentares durante a crise, frente a hipóteses correntes na literatura. Em nossa análise, um dado em especial salta aos olhos: os parlamentares estaduais, durante a crise de 2020, demonstraram uma certa preferência por benefícios que atingem a classe média. Os benefícios destinados a esse setor foram bem maiores em número e intensidade que os benefícios destinados às classes mais baixa e mais alta. Esse padrão é bem mais pronunciado que um outro padrão bem mais apontado na literatura: a tendência aos benefícios particularistas, sejam eles locais ou setoriais (AMES, 2003; CASTRO; ANASTASIA; NUNES, 2009; MELO, 2011; NUNES, 2012). Para proteger a classe média da crise, os parlamentares chegaram mesmo a atuar de um modo que contradiz o comportamento esperado pela literatura: eles impuseram perdas concentradas a determinados setores econômico para fornecer ganhos difusos para os consumidores de classe média (ARNOLD, 1992; WILSON, 1984), ou seja, promoveram medidas redistributivas (LOWI, 1964).

Portanto, esse artigo pretende se debruçar sobre as seguintes questões específicas: (1) quais parlamentos foram mais ativos durante a crise? (2) As assembleias abandonaram sua relação tradicional de submissão com os governos estaduais e foram mais proativas na formulação de políticas públicas? (3) quais as áreas de política mais comuns das leis estaduais aprovadas? (4) Quais grupos foram o alvo preferencial de benefícios e perdas das leis aprovadas?

$\mathrm{O}$ artigo se divide da em seis sessões, incluindo essa introdução. Na próxima seção faremos uma revisão bibliográfica sobre características básicas do federalismo brasileiro e sobre o comportamento parlamentar estadual. Na seção seguinte discorreremos sobre a metodologia de análise empregada nesse artigo. A sessão 4 traz de uma visão geral das leis aprovadas, onde abordaremos as questões 1 e 2 . A sessão 5 discorre sobre o público-alvo das propostas e levanta a hipótese do viés pró-classe média (questões 3 e 4). Por fim existe uma sessão de conclusão.

\section{Revisão bibliográfica}

Autores clássicos da teoria do federalismo viam a autonomia estadual como um caminho para possibilitar a maior experimentação de políticas públicas, possibilitando assim uma melhor possibilidade de se encontrar soluções inovadoras paras os desafios sociais (OATES, 1999; TIBEOUT, 1956; WEINGAST, 1995). Contudo, essa possibilidade sempre foi vista com ceticismo no Brasil, onde os Estados são vistos como fracos e pouco autônomos (ABRUCIO, 1998; ARRETCHE, 2013; GUICHENEY; JUNQUEIRA; ARAÚJO, 2018). Em particular, as Assembleias Legislativas estaduais ocupam um lugar ainda mais desprivilegiado que os 
Executivos estaduais na federação brasileira. Ao contrário do modelo americano, em que cada Estado possui um amplo espaço constitucional para a produção de legislação local, no Brasil, a maior parte dos regulamentos - como legislação civil, penal e tributária - é federal (TOMIO; ORTOLAN; CAMARGO, 2010). Do pouco espaço que sobra para a atuação estadual, basicamente atribuições comuns e concorrentes (artigos 23 e 24 da Constituição Federal), boa parte é de iniciativa exclusiva do Poder Executivo, como leis que regulam carreiras públicas ou estabelecem a criação ou alteração de órgãos públicos. Paralelo a isso, boa parte dos estudos sobre os legislativos estaduais enxerga nos parlamentares estaduais uma versão piorada de seus congêneres federais. Os deputados estaduais seriam tendentes ao localismo, ao fisiologismo e à submissão ao Executivo local (ABRUCIO, 1998; CASTRO; ANASTASIA; NUNES, 2009; GRAÇA, 2016; MELO, 2011; NUNES, 2012; TOMIO; RICCI, 2012).

Como veremos, o contexto especial do ano de 2020, marcado pela maior pandemia em um século, além de uma crise econômica profunda, alterou os incentivos parlamentares. Parte das Assembleias estaduais abandonaram a postura tradicionalmente passiva diante do Executivo e passaram a ativamente produzir políticas públicas. Uma hipótese para isso seria que o caráter centralizado da federação brasileira ocorre porque no conflito entre normas centrais e locais, sempre prevalece as centrais (ARRETCHE, 2002; GUICHENEY; JUNQUEIRA; ARAÚJO, 2018). Porém, no contexto atual, a relativa ausência de regras federais deu maior margem às ações locais. Além disso, os casos mostraram que, nesse contexto, a política local também importa. Casos em que o governo local também foi pouco ativo em produzir políticas públicas deu maior espaço para o protagonismo do Legislativo local. Em outros casos, parece ter havida uma colaboração voluntária entre o governador local e a Assembleia. Talvez pela primeira vez, os Legislativos estaduais tiveram um espaço relativamente amplo para produzir políticas públicas de forma autônoma. Cada parlamento usou essa autonomia de acordo com seu "estilo". A ciência política brasileira tradicionalmente deu pouco espaço para o conteúdo das políticas locais ${ }^{3}$, esse estudo pretende preencher essa lacuna utilizando o contexto privilegiado de 2020 onde houve grande efervescência de produção local de políticas públicas.

\section{Metodologia}

Esse artigo procurou realizar uma pesquisa de caráter quantitativo exploratório, ou seja, procurou analisar os casos utilizando sobretudo a estatística descritiva e a análise de conteúdo das leis estaduais. Procuramos fazer uma "imersão nos dados", lendo e analisando as leis aprovadas, bem como os projetos de lei e suas justificativa, para podermos encontrar padrões e fornecer informações úteis aos leitores. O estudo exploratório, apesar de não ser o melhor meio de testar hipóteses do ponto de vista científico, é um ótimo meio de se criar hipóteses testáveis. Assim, o

\footnotetext{
${ }^{3}$ Exceção feita a Tomio \& Ricci (2012).
} 
estudo exploratório visa formar uma imagem geral dos fenômenos, uma big Picture, na qual outros pesquisadores poderão recortar cada ponto específico e utilizar métodos mais rigorosos de teste de hipóteses. É importante considerar que sem boas hipóteses, não se pode chegar em boas conclusões, mesmo utilizando-se de metodologia sofisticada.

A amostra escolhida são todas as leis (ordinárias e complementares) aprovadas pelas Assembleias Estaduais de março a agosto de 2020, que visam combater a pandemia da Covid-19 e seus efeitos sobre a população ${ }^{4}$. Foram recolhidas as leis de 16 Estados: AM, AP, BA, ES, GO, MA, MG, MT, PA, PB, PE, PI, PR, RO, RS, SP; representado todas as regiões brasileiras. As leis da amostra foram selecionadas a partir de um critério de palavras-chave. Foram consideradas as normas que continham pelo menos uma das seguintes palavras: "covid", "coronavírus", "pandemia", "calamidade" ou "emergência". Após a seleção via palavras-chave, verificamos cada lei para checar se elas realmente dizem respeito à crise da Covid, excluindo as normas que não relacionadas ao tema. Temas estritamente orçamentários, como abertura de créditos suplementares e remanejamento de fundos, foram excluídas da análise. No total 309 leis foram selecionadas.

Os critérios teóricos utilizadas para a construção de cada variável da amostra estão descritos abaixo, juntos com a análise. O banco de dados completo da análise, o livro de códigos e os scripts computacionais para a construção de cada figura desse artigo estão disponíveis no anexo metodológico 5 .

\section{Padrões de ação das Assembleias durante a crise do Covid-19}

$\mathrm{Na}$ Tabela 1 e no mapa da esquerda da Figura 1 podemos ver a quantidade de leis aprovadas em cada unidade federativa. Para facilitar a análise, na Tabela 1, as legislações de iniciativa dos parlamentares foram mostradas separadamente das de iniciativa do Poder Executivo. Podemos ver que a quantidade leis aprovadas varia enormemente entre os Estados. Não existe nenhuma indicação que o número de parlamentares em cada Assembleia esteja correlacionado com o número de leis aprovadas. Parlamentos com muitos deputados, como São Paulo e Rio Grande do Sul, tiveram um reduzidíssimo número de leis aprovadas, enquanto os parlamentos da Paraíba, Mato Grosso e Maranhão aprovaram dezenas de leis. Aparentemente, foi a postura diante da crise, de delegação de poder ao Executivo ou de protagonismo do Legislativo, que determinou o número de leis aprovadas. E, como veremos, essa postura foi muito importante para o conteúdo das leis aprovadas. As Assembleias que foram mais ativas na produção legal, de

\footnotetext{
${ }^{4}$ Nenhuma lei sobre o assunto aprovada em janeiro e fevereiro. Como explicado acima, leis específicas de saúde foram excluídas da análise.

${ }^{5}$ https://github.com/Murilojunqueira/Covid19Leg
} 
fato, aprovaram políticas qualitativamente diferentes das Assembleias que delegaram poder ao

Executivo.

Tabela 1 - Número de Leis aprovadas por estado

\begin{tabular}{|c|c|c|c|c|c|c|c|}
\hline $\mathbf{U F}$ & $\begin{array}{l}\text { Total } \\
\text { Leis }\end{array}$ & $\begin{array}{c}\text { Leis } \\
\text { Executivo }\end{array}$ & $\begin{array}{c}\text { Leis } \\
\text { Legislativo }\end{array}$ & $\begin{array}{c}\% \\
\text { Executivo }\end{array}$ & $\begin{array}{c}\text { Padrão } \\
\text { Executivo- } \\
\text { Legislativo }\end{array}$ & Governador & $\begin{array}{c}\text { Partido } \\
\text { Governador }\end{array}$ \\
\hline PB & 63 & 1 & 62 & $2 \%$ & protagonista & João Azevedo & PSB \\
\hline MG & 44 & 5 & 39 & $11 \%$ & protagonista & Romeu Zema & NOVO \\
\hline MT & 37 & 4 & 33 & $11 \%$ & protagonista & $\begin{array}{l}\text { Mauro } \\
\text { Mendes }\end{array}$ & DEM \\
\hline PE & 35 & 6 & 29 & $17 \%$ & protagonista & Paulo Câmara & PSB \\
\hline MA & 31 & 11 & 20 & $35 \%$ & homologatória & Flávio Dino & PC do B \\
\hline $\mathbf{A M}$ & 18 & 5 & 13 & $28 \%$ & homologatória & Wilson Lima & PSC \\
\hline RO & 17 & 4 & 13 & $24 \%$ & homologatória & $\begin{array}{l}\text { Marcos } \\
\text { Rocha }\end{array}$ & PSL \\
\hline $\mathbf{B A}$ & 12 & 8 & 4 & $67 \%$ & delegativa & Rui Costa & PT \\
\hline PR & 12 & 5 & 7 & $42 \%$ & delegativa & $\begin{array}{l}\text { Ratinho } \\
\text { Júnior }\end{array}$ & PSD \\
\hline ES & 9 & 2 & 7 & $22 \%$ & delegativa & $\begin{array}{c}\text { Renato } \\
\text { Casagrande }\end{array}$ & PSB \\
\hline GO & 6 & 2 & 4 & $33 \%$ & delegativa & $\begin{array}{l}\text { Ronaldo } \\
\text { Caiado }\end{array}$ & DEM \\
\hline PA & 6 & 3 & 3 & $50 \%$ & delegativa & $\begin{array}{l}\text { Helder } \\
\text { Barbalho }\end{array}$ & MDB \\
\hline PI & 6 & 2 & 4 & $33 \%$ & delegativa & $\begin{array}{l}\text { Wellington } \\
\text { Dias }\end{array}$ & PT \\
\hline $\mathbf{A P}$ & 5 & 4 & 1 & $80 \%$ & delegativa & Waldez Góes & PDT \\
\hline $\mathbf{R S}$ & 5 & 4 & 1 & $80 \%$ & delegativa & Eduardo Leite & PSDB \\
\hline SP & 3 & 2 & 1 & $67 \%$ & delegativa & João Doria & PSDB \\
\hline
\end{tabular}

Fonte: Elaboração própria

Alguns estados, como Maranhão e Bahia, tiveram um protagonismo legislativo do Executivo. No caso do Maranhão, a maior parte das leis aprovadas foram fruto de medidas provisórias, que são permitidas pela Constituição estadual. Certamente, as medidas provisórias facilitaram a estratégia extremamente ativa do governador maranhense no enfretamento da crise, que provavelmente foi o mais intervencionista da amostra ${ }^{6}$. Contudo, outros estados onde o Executivo também tem o poder de editar medidas provisórias, como Santa Catarina e Piauí, se abstiveram de utilizar tal instrumento. Do lado oposto, alguns governadores foram bem pouco ativistas do ponto de vista legislativo, como Paraíba, São Paulo, Piauí e Goiás. O caso da Paraíba parece ser sus genesis, pois foi o Estado que mais aprovou leis, mas apenas uma norma foi de

\footnotetext{
${ }^{6} \mathrm{O}$ Maranhão proibiu o aumento de preços de energia, água e internet durante a crise, bem como determinou a redução forçada de mensalidades escolares e planos de saúde. Também houve proibição de aumentos de preços de "produtos básicos" durante a crise, sem uma devida justificativa. Também houve mudanças importantes com relação à administração pública e legislação tributária. Não é objetivo desse trabalho avaliar se as medidas adotadas foram adequadas ou efetivas, apenas analisamos o "estilo" de gerenciamento da crise.
} 
autoria do Executivo. Não existe evidência de que isso tenha sido devido à ausência de protagonismo do Governador do Estado (SERAFIM; MENEZES, 2020), mas sim de um autêntico trabalho de colaboração com a Assembleia estadual, resultando, inclusive, em uma certa delegação de poder do Executivo ao Legislativo

Figura 1 - Padrões de Legislação a Respeito do Covid
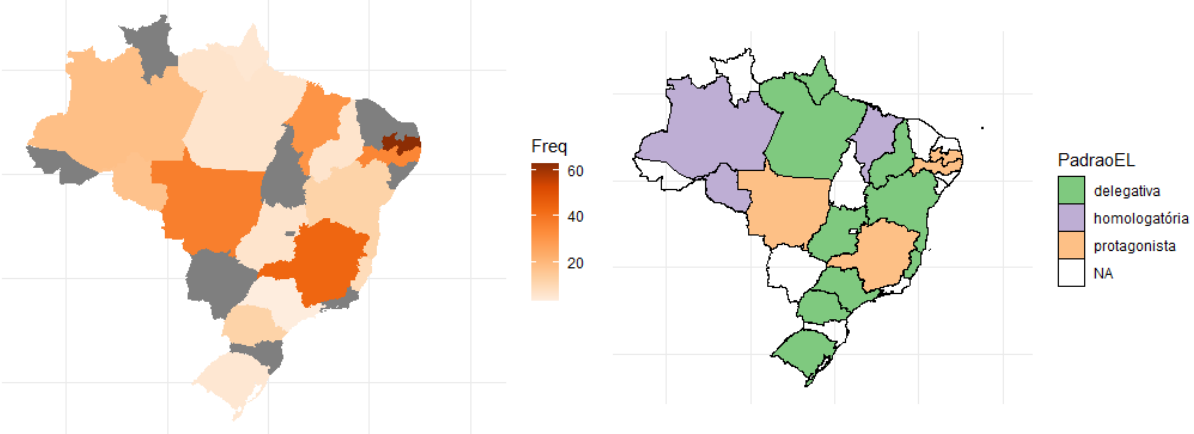

Fonte: Elaboração própria

Podemos classificar o padrão de relações entre Legislativo e Executivo durante a crise por dois critérios: quanto ao número de leis aprovadas e pela autoria das leis (se do Poder Executivo ou dos próprios parlamentares). Quanto ao número de leis aprovadas, as Assembleias podem ter um padrão delegativo, ou seja, aprovar poucas leis, deixando que a crise seja gerida pelo Poder Executivo, ou então ter um padrão ativista, aprovando um extenso arcabouço de normas. Quanto à autoria das leis, as Assembleias podem estabelecer um padrão homologatório em relação ao Executivo, apenas aprovando as leis enviadas pelo governador, ou então ter um padrão protagonista, aprovando sobretudo leis de autoria dos deputados. Porém, não faz sentido que um parlamento seja ao mesmo tempo delegativo e protagonista, pois se ele aprova poucas leis, naturalmente ele não está sendo protagonista. Assim, resolvemos classificar as relações Executivo-Legislativo nas Assembleias estaduais em três tipos: as Assembleias delegativas (poucas leis aprovadas), homologatórias (muitas leis aprovadas, sendo grande parte de autoria do Executivo) e protagonista (muitas leis aprovadas, sendo a maioria de autoria do Legislativo). As linhas de corte foram decididas a partir das quebras naturais dos dados da Tabela 1, ou seja, os pontos onde existem "saltos" nos valores. Uma Assembleia foi considerada delegativa se aprovou menos de 15 leis durante o período. Foram consideradas Assembleias homologatórias as que aprovaram mais de 15 leis, sendo pelo menos de $20 \%$ de autoria do Poder Executivo. As Assembleias protagonistas aprovaram mais de 15 leis e menos de $20 \%$ delas de autoria do 
Executivo $^{7}$. Por esse critério, as Assembleias da Paraíba, Pernambuco, Minas Gerais e Mato Grosso foram consideradas protagonistas, enquanto as Assembleias do Maranhão, Amazonas e Rondônia foram consideradas homologatórias. Os demais parlamentos da amostra foram considerados delegativos. Podemos ver os padrões descritos no mapa da direita da Figura 1.

O caso de Minas Gerais mostra um interessante caso onde a Assembleia foi mais que protagonista, mas de certa forma substituiu a liderança do Governador, que, tal como o governo federal, foi relativamente ausente na crise (SILAME; GOMES; ALMEIDA, 2020). A Assembleia mineira além de ter aprovado muitas leis, aprovou muitas intervenções econômicas (como congelamento de preços e reduções forçadas de mensalidades escolares e planos de saúde) o que contrasta com o discurso pró livre mercado do governador. Também podemos observar que os deputados autores das leis mineiras englobam todos os aspectos ideológicos, inclusive a esquerda, o que demonstra que a produção de leis no parlamento mineiro foi protagonizada pelo Legislativo e não por uma articulação liderada pelo Executivo. Possivelmente, o caso do Mato Grosso seja similar ao caso mineiro quanto a esse aspecto.

\section{Políticas e áreas de política mais frequentes durante a crise}

A Figura 2 aborda as áreas de política aprovadas por lei. É importante ressaltar que a figura diz respeito a áreas de políticas e não a leis. Uma lei pode conter mais de uma política. Por sua vez, uma política pode englobar mais de uma área. Por exemplo, uma lei que proíba temporariamente o corte dos serviços de energia das famílias de baixa renda é tanto uma política tanto de assistência social quanto de serviços de utilidade pública; por isso, é contada duas vezes na Figura 2. Uma lei que proíba que os planos de saúde privada limitem o tempo de internação em casos de Covid, será contada tanto como uma política de saúde quanto de direito do consumidor, e assim por diante. As políticas específicas de saúde estão excluídas da Figura 2 e do restante dessa análise, pois elas foram alvo de uma abordagem especial, em outro artigo ${ }^{8}$.

\footnotetext{
${ }^{7} \mathrm{O}$ valor de $20 \%$ pode parecer pouco, mas esse parece ser um ponto de corte nos dados, principalmente nas Assembleias que aprovaram muitas normas. Naturalmente, quando o número de lei aprovadas cresce, a dominância do Executivo cai.

${ }^{8}$ Se a saúde estivesse no gráfico dois, certamente ela seria a política mais frequente. Houve 133 políticas de saúde, 22 de autoria do Executivo e 111 de autoria do Legislativo.
} 
Figura 2 - Áreas de Política
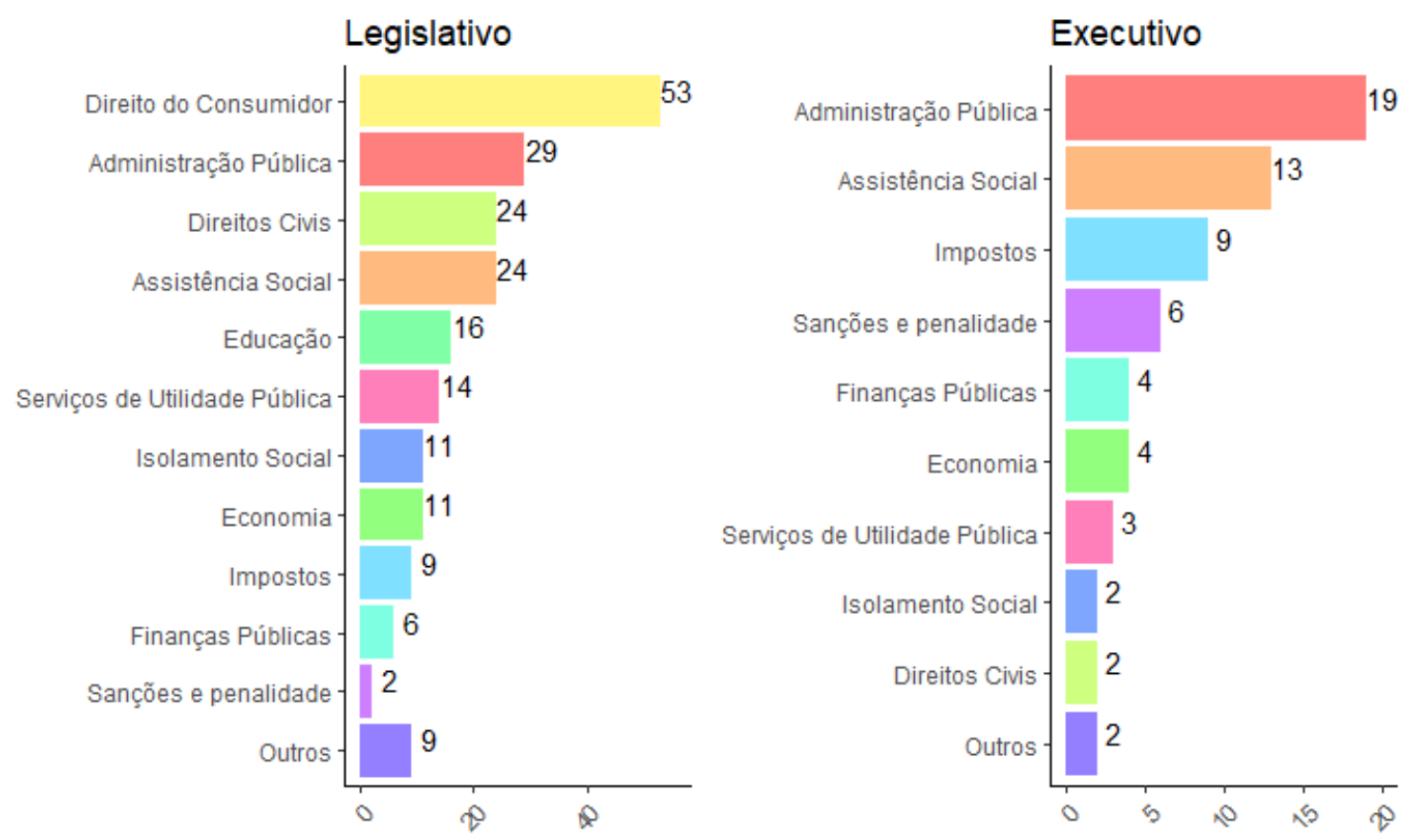

Fonte: Elaboração própria

Podemos perceber que o foco dos parlamentares foi sobretudo em direito do consumidor. As políticas favoritas dos parlamentares foram: proibir a majoração, sem justa causa do preço de serviços e produtos básicos (adotada por 9 Estados), determinação de redução de mensalidades escolares (7 Estados), determinação de remarcação, sem multa, de viagens aéreas e pacotes turísticos (5 estados), suspensão da cobrança de franquia e do corte do serviço por falta de pagamento em serviços de TV e internet (4 Estados) e fim da carência em planos de saúde (2 estados). Essas medidas denotam um claro aumento da tendência ao aumento do intervencionismo econômico durante a crise, o que contrasta com o comportamento normal dos parlamentares estaduais.

Enquanto as leis de autoria do Executivo que tratam da administração pública se concentram nas áreas de contratação e gestão de pessoas (onde somente o governador pode propor leis), as leis de autoria dos parlamentares dizem respeito a normas de transparência. Cinco Estados (AM, MG, MT, PB) impuseram aos governadores regras de transparência mais rígidas sobre contratos e medidas administrativas de enfrentamento a crise. Na Paraíba, essas regras foram estendidas também aos municípios. Os deputados também se preocuparam com os candidatos em concursos para a administração estadual, suspendendo os prazos de validade dos concursos (6 estados). De forma talvez surpreendente, em apenas três Estados foram criadas regras de compras e contratações mais flexíveis para enfretamento da pandemia (ES, PB e PE), algo que poderia levar a um uso oportunista da crise para casos de corrupção. 
Os direitos civis também foram alvo dos parlamentares. Oito Estados criaram políticas de acolhimento a mulheres vítimas de violência doméstica durante a quarentena. Todas as propostas foram de autoria de parlamentares. Enquanto a proposta de proibição das notícias falsas (fakenews) ainda patina do Congresso Nacional, sete estados criaram leis locais que proíbem e estabelecem multas para a propagação de informações falsas a respeito da pandemia. Em apenas um caso (Bahia) a proibição de fakenews foi de autoria do Executivo. Ainda sobre os direitos civis, quatro estados (AM, ES, PR, RO) estabeleceram que igrejas e cultos são atividades essenciais durante a pandemia, limitando a possibilidade de realizar quarentena para essas atividades. Todas as leis que beneficiavam as atividades religiosas foram de autoria dos parlamentares.

As medidas de assistência social mais populares foram a criação de transferências de renda e redução nos preços dos serviços de utilidade pública, como energia elétrica, água e gás encanado. Sete estados promoveram benefícios com relação aos serviços de utilidade pública que poderiam ser tanto um desconto direto, quanto um auxílio a famílias de baixa renda ou simplesmente proibindo as empresas de cortarem o fornecimento em casos de falta de pagamento. Desses benefícios, três foram iniciativa do governador do Estado (BA, PA, MT) e quatro forma iniciativa parlamentar (MG, PB, PE e PR). Os governadores tiveram como política de assistência social favorita a criação de programas de transferência de renda. Dos oito estados que criaram programas de transferência de renda, cinco o fizeram por iniciativa do governador (AM, AP, BA, PR, RO) e três por iniciativa parlamentar (MG, MT, PB). Com relação à educação, a política mais popular foi a redução das mensalidades de escolas e universidades privadas, proposta em oito estados, todos por iniciativa parlamentar.

Com relação às medidas de isolamento social, a maioria das medidas foram em sentido negativo, retirando setores do isolamento determinado por decreto, como no caso da retirada de atividades religiosas do isolamento. Apenas um Estado (Rondônia) criou leis de punição por multa para desrespeito às medidas de distanciamento social, por iniciativa do governador.

\section{Produção legislativa e público-alvo das propostas}

Quanto aos setores afetados, classificamos as políticas por dois critérios: quanto às categorias sociais envolvidas (setor social, empresas, pequenos empreendimentos, categorias profissionais ou "geral") e quando à renda do público-alvo (baixa, média-baixa, média, médiaalta, alta e "geral"). Quantos às categorias sociais, o setor social envolve desde agrupamentos amplos, como mulheres, idosos, famílias de baixa renda, famílias de renda média, ou alunos da rede pública; até agrupamentos mais específicos como indígenas, internos do sistema prisional ou população de rua. Os pequenos empreendimentos são uma espécie de meio termo entre o setor social e as empresas, como microempreendedores, cooperativas e autônomos. Empresas e 
categorias profissionais são classificações evidentes por si. Por fim, a categoria "geral" diz respeito a benefícios que não podem ser atribuídos a um setor específico, como normas de higiene ou corte de gastos públicos.

Figura 4 - Categorias sociais Beneficiadas pelas políticas
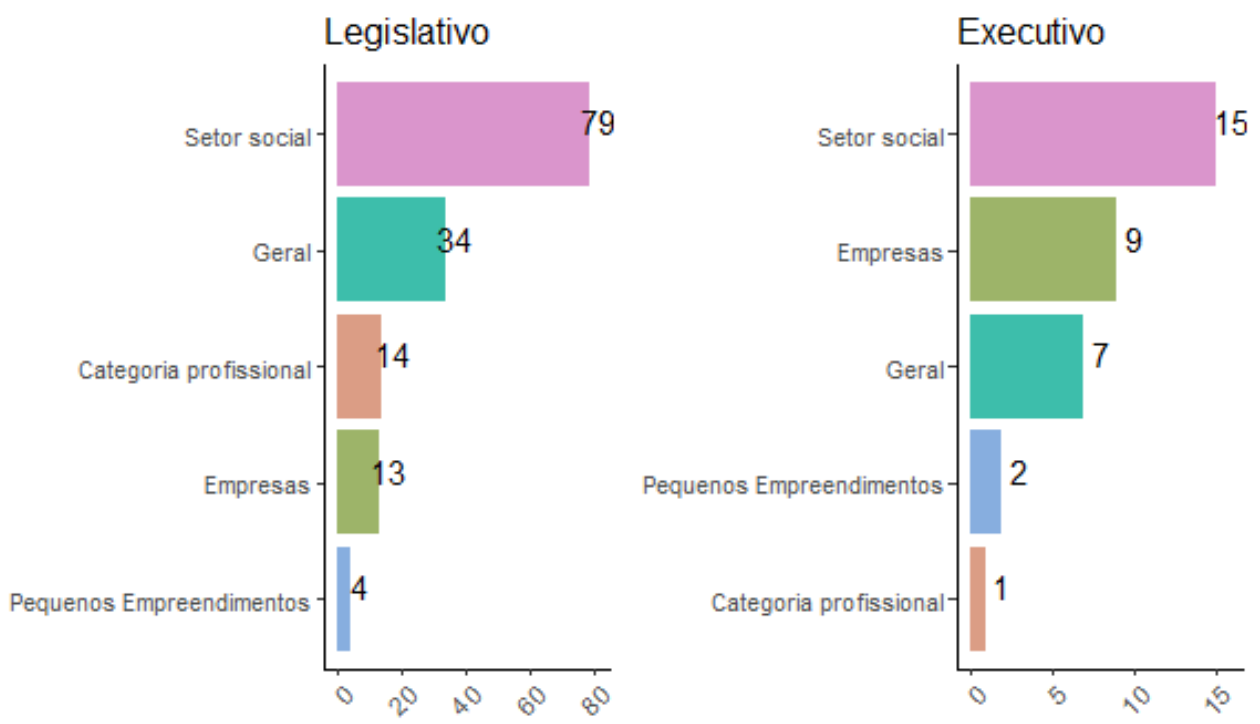

Fonte: Elaboração própria

A Figura 4 mostra as categorias mais beneficiadas pelas políticas propostas pelos legislativos e pelos executivos ${ }^{9}$. Podemos perceber que ambos demonstram uma predileção por políticas que beneficiem uma categoria social específica. Particularmente, as políticas de assistência social, direitos civis e parte das políticas de direito do consumidor abordadas anteriormente tem por alvo o setor social. Talvez o ponto que mais chame a atenção na Figura 4 é a relativa desatenção dos legisladores, em meio a uma gravíssima crise econômica, com medidas de apoio aos pequenos empreendimentos e mesmo às grandes empresas - embora os governadores tenham sido um pouco mais proativos nessa questão. Uma possível explicação para essa relativa inatividade das Assembleias em relação à economia seja uma delegação de responsabilidades aos Executivos estaduais ou mesmo ao governo federal. Mas deve-se ressaltar que os parlamentos estaduais se dedicaram fortemente em produzir políticas que beneficiam a classe média, como mostra a Figura 5.

\footnotetext{
${ }^{9}$ As políticas de saúde não estão inclusas nas figuras 4 e 5, mas se estivessem, quase todas estariam classificadas como de caráter "geral". As políticas de saúde dizem respeito à saúde preventiva, gestão hospitalar e fornecimento de dados; todas essas medidas não afetam um setor específico, mas a toda a população.
} 
Figura 5 - Grupos beneficiados de acordo com a classe de renda
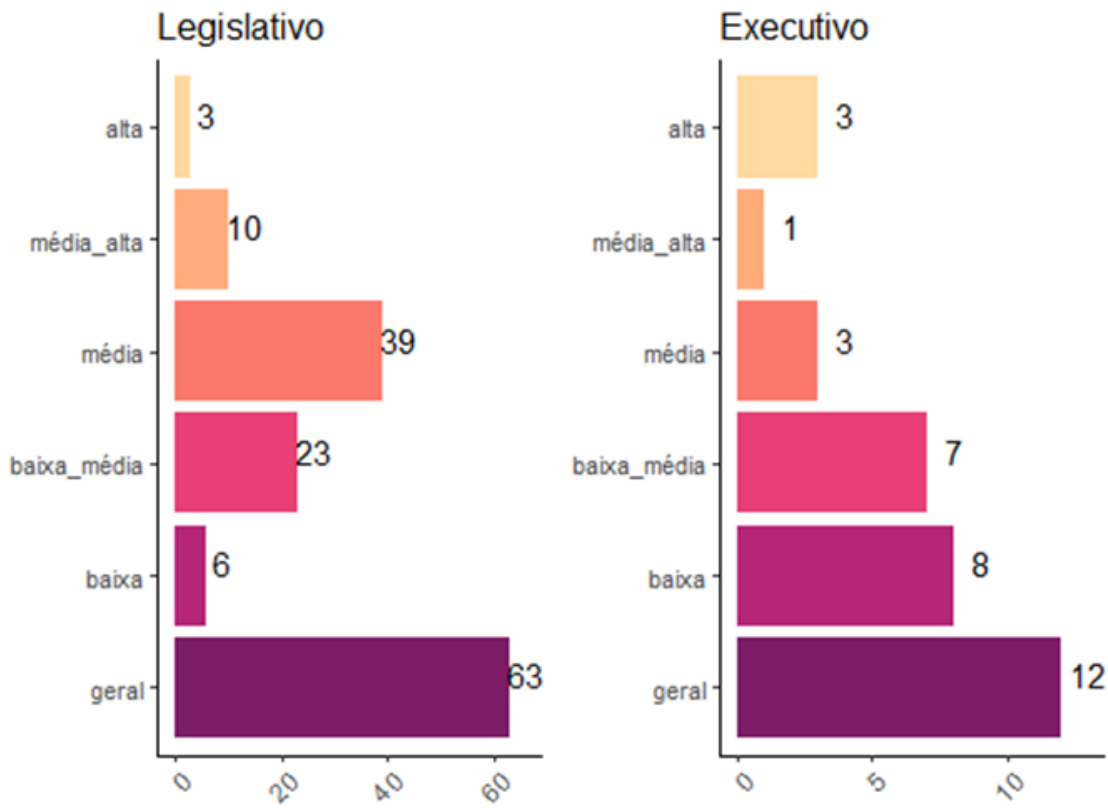

Fonte: Elaboração própria.

A Figura 5 mostra os grupos beneficiados pelas políticas estaduais de acordo com uma estimativa de renda. O critério para estimar a renda do público-alvo da proposta não é objetivo, tal como a estimativa de renda feita por pesquisas domiciliares. Porém, raramente é objetiva a avaliação que os próprios políticos fazem do público que será beneficiado por determinada proposta. O critério utilizado serve como modelo heurístico para avaliar, de forma exploratória, o público-alvo das políticas. Foram consideradas políticas que beneficiam a baixa renda todas as políticas que envolviam a análise das condições socioeconômicas das famílias, de modo a atingir especificamente os mais pobres. Foram consideradas políticas para a renda baixa-média as políticas que visavam prioritariamente atingir os mais pobres, mas podem eventualmente beneficiar a classe média. O exemplo mais comum são descontos nos serviços de utilidade pública, como água e energia. Essa proposta certamente fará uma diferença maior para a classe baixa, mas trará algum alívio para o orçamento da classe média. Descontos no IPVA também foram classificados como atingindo a renda baixa-média, embora sua lógica seja a oposta do exemplo anterior: beneficiam sobretudo a classe média, podendo atingir algumas pessoas da classe baixa que eventualmente possuam automóvel. Políticas que beneficiam pequenos empreendimentos, como cooperativas, pequenos agricultores e microempreendedores, também foram classificadas como baixa-média. Foram classificados como beneficiando a classe média as políticas destinadas a reduzir os preços ou aumentar os benefícios de serviços sofisticados, que raramente estão disponíveis para a classe baixa, como escolas particulares, planos de saúde privada, viagens aéreas e TV por assinatura. Ajuda a pessoas que estão na fila de espera de 
concursos públicos também foram consideradas como destinadas à classe média. Políticas que beneficiam os funcionários públicos em exercício foram classificados como de renda média-alta, exceção feita aos professores da rede pública e aos policiais, que foram classificados como renda média. Políticas que visam beneficiar pequenas e médias empresas (mas não microempresas), como pousadas, hotéis, restaurantes e o setor de entretenimento também foram classificadas como média-alta. Políticas que visam beneficiar empresas que são por natureza grandes (agronegócio, usinas de açúcar, companhias aéreas, etc) foram classificadas como de alta renda. Por fim, políticas que não tem por alvo uma faixa de renda específica, como proibição de fakenews, medidas de acolhimento a mulheres em situação de violência, proibição de fogueiras e São João ou estabelecer que atividades religiosas são essenciais, foram consideradas de caráter "geral".

Dada essa classificação, podemos perceber que os parlamentares demonstram uma nítida predileção por políticas que favorecem a classe média, principalmente via alterações no direito do consumidor. O mais surpreendente é que muitos desses benefícios vem às custas de outros setores privados, muitos deles de alta renda, como escolas particulares e planos de saúde privados. Uma política muito popular na pandemia foi estabelecer a redução forçada das mensalidades escolares, em razão da ausência de aulas presenciais. Também foi comum proibir a carência em planos de saúde privada ou proibir limites ao tempo de internação. Dois estados (PB e RO) suspenderam o pagamento de empréstimos consignados de todos os funcionários públicos, sem a necessidade de comprovação da impossibilidade de pagamentos ou problemas de saúde. Mesmo muitas das propostas classificadas como de benefícios gerais, como higiene em bancos e supermercados, ou assistência a mulheres vítimas de violência, talvez só tenham sido frequentes por também terem um impacto visível na classe média. Não é nosso objetivo aqui discutir o mérito dessas medidas, mas, aparentemente, o foco dos parlamentares foi muito intenso nessas áreas, sendo que outras, como saúde dos indígenas, população de rua ou população carcerária mereceram atenção reduzida. Até mesmo a saúde dos trabalhadores pobres em serviços essenciais, como a crescente população ocupada nos serviços de entrega, foi alvo de poucas políticas. Apenas dois Estados (PB e PE) prescreveram normas de higiene nesses serviços, e mesmo assim não está claro se o objetivo dessas normas era proteger o trabalhador ou o consumidor.

\section{Conclusão}

A análise mostrou que as políticas de combate à crise econômica e social gerada pelo coronavírus variou enormemente entre os Estados. Alguns parlamentos estaduais se mostraram protagonistas, aprovando extensa legislação sobre o tema, inclusive, rompendo com o padrão de subordinação em relação ao Executivo que caracteriza as Assembleias estaduais. Principalmente nos casos em que os parlamentos foram mais ativos, uma série de intervenções sociais e 
econômicas foram aprovadas, chegando ao ponto de impor perdas concentradas e ganhos difusos - algo incomum na lógica parlamentar. No entanto, grande parte desses benefícios foi destinado à classe média. Propostas destinadas à recuperação econômica de empresas, apoio aos pequenos negócios e políticas de ajuda a pessoas de maior vulnerabilidade tiveram uma atenção menor. Excede o escopo desse trabalho procurar as causas da predileção dos parlamentares por políticas pró-classe média. Podemos especular que isso talvez tenha ocorrido por uma maior identificação dos parlamentares com esse segmento social, ou então por uma eventual busca de benefícios políticos ou atenção da imprensa ou ainda delegação da responsabilidade pelos demais setores para outros poderes e níveis federativos. Por enquanto, é mister mencionar que essa é uma tendência até o momento pouco explorada pela literatura do comportamento legislativo estadual, que certamente merece renovada atenção nos estudos políticos futuros.

\section{Referências}

ABRUCIO, Fernando Luiz. Os barões da Federação: os governadores e a redemocratização brasileira. São Paulo: HUCITEC, 1998.

AMES, Barry. Os entraves da democracia no Brasil. Rio de Janeiro: FGV, 2003.

ARNOLD, R. Douglas. The Logic of Congressional Action. New Haven, CT: Yale University Press, 1992.

ARRETCHE, Marta. Federalismo e relações intergovernamentais no Brasil: a reforma de programas sociais. Dados, v. 45, n. 3, p. 431-458, 2002.

ARRETCHE, Marta. Quando instituições federativas fortalecem o governo central? Novos Estudos, v. 95, p. 39-57, 2013.

ARRETCHE, Marta. Quem taxa e quem gasta: a barganha federativa na federação brasileira. Revista de Sociologia e Política, n. 24, p. 69-85, 2005.

CASTRO, Mônica Mata Machado De; ANASTASIA, Fátima; NUNES, Felipe. Determinantes do comportamento particularista de legisladores estaduais brasileiros. Dados, v. 52, n. 4, p. 9611001, 2009.

GRAÇA, Luís Felipe Guedes da. O Governo do Estado e a Assembleia Legislativa: Entre a Submissão e os Limites da Independência. Curitiba: Appris, 2016.

GUICHENEY, Hellen; JUNQUEIRA, Murilo de Oliveira; ARAÚJO, Victor. O debate sobre o federalismo e suas implicações para a governabilidade no Brasil (1988-2015). Revista

Brasileira de Informação Bibliográfica em Ciências Sociais - BIB, v. 83, p. 69-92, 2018.

LEVI, Margaret. Of rule and revenue. Los Angeles: University of California Press, 1989.

LOWI, Theodore J. American Business, Public Policy, Case-Studies, and Political Theory.

World Politics, v. 16, n. 4, p. 677-715, 1964. 
MELO, Carlos Ranulfo. Individualismo e partidarismo em doze estados Brasileiros. Revista Brasileira de Ciências Sociais, v. 26, n. 75, p. 57-71, 2011.

NUNES, Felipe. What is the Best Strategy to Obtain Legislative Support? Survey Evidence from Brazilian State Assemblies. Brazilian Political Science Review, v. 6, n. 2, p. 88-113, 2012.

OATES, Wallace E. An Essay on Fiscal Federalism. Journal of Economic Literature, v. 37, n. 3, p. 1120-1149, 1999.

SERAFIM, Lizandra; MENEZES, Henrique Zeferino de. Especial ABCP: As ações da Paraíba no enfrentamento à pandemia. Disponível em: https://cienciapolitica.org.br/analises/especialabcp-4a-edicao-governos-estaduais-e-acoes/artigo/especial-abcp-acoes-paraiba-enfrentamentopandemia. Acesso em: 15 set. 2020.

SILAME, Thiago Rodrigues; GOMES, Larissa Peixoto; ALMEIDA, Helga do Nascimento de. Especial ABCP: As ações de Minas Gerais no enfrentamento à pandemia. Disponível em: https://cienciapolitica.org.br/analises/especial-abcp-4a-edicao-governos-estaduais-eacoes/artigo/especial-abcp-acoes-minas-gerais-enfrentamento. Acesso em: 15 set. 2020.

TIBEOUT, Charles M. A Pure Theory of Local Expenditures. Journal of Political Economy, v. 64, n. 5 , p. 416-424, 1956.

TOMIO, Fabrício Ricardo de Limas; ORTOLAN, Marcelo Augusto Biehl; CAMARGO, Fernando Santos. Análise Comparativa dos Modelos de Repartição de Competências

Legislativas nos Estados Federados. Revista da Faculdade de Direito UFPR, v. 51, 2010.

TOMIO, Fabrício Ricardo de Limas; RICCI, Paolo. O governo estadual na experiência política Brasileira: Os desempenhos legislativos das assembleias estaduais. Revista de Sociologia e Política, v. 20, n. 41, p. 193-217, 2012.

WEINGAST, Barry. The economic role of political institutions: market preserving federalism and economic development. Journal of Law, Economics, and Organization, v. 11, n. 1, p. 1, 1995.

WILSON, James Q. Politics of Regulation. In: FERGUSON, THOMAS; ROGERS, JOEL (org.). The Political economy: readings in the politics and economics of American Public Policy. New York-NY: Routledge, 1984. p. 81-103. 